Derecho natural de asociación en la figura de la coalición electoral en México

Natural right of association in the electoral coalition figure in

Mexico

Autor: Gabriela Aguado Romero

DOl: https://doi.org/10.25058/1794600X.990 


\section{DERECHO NATURAL DE ASOCIACIÓN EN LA FIGURA DE LA COALICIÓN ELECTORAL EN MÉXICO*}

NATURAL RIGHT OF ASSOCIATION IN THE ELECTORAL COALITION FIGURE IN MEXICO

DIREITO NATURAL DE ASSOCIAÇÃO NA FIGURA
DA COLIGAÇÃO ELEITORAL NO MÉXICO

\section{RESUMEN}

La asociación como derecho natural, y llevada a la práctica como un derecho político-electoral, es el punto en el cual los ciudadanos y el Estado se vinculan entre sí, ya que permite a los individuos autorizados para ello participar e intevenir en los asuntos políticos del país y alcanzar los fines comunes por una unión de fuerzas. El derecho de asociación en materia político-electoral ha ido evolucionando como un derecho natural de contenido progresivo ${ }^{1}$, el objetivo de asociarse en materia política es la protección de los derechos y resistirse a la opresión, sin embargo aún cuando se reconoce que el derecho de
Gabriela Aguado Romero ${ }^{a}$ aguadogabriela@hotmail.com

Fecha de recepción: diciembre 03 de 2018 Fecha de revisión: enero 28 de 2019 Fecha de aceptación: marzo 08 de 2019

1. Al respecto, cabe recordar los principios de los derechos humanos consagrados a nivel nacional dentro del artículo $1^{\underline{o}}$ Constitucional: universalidad, interdependencia, indivisibilidad y progresividad.

\section{*Artículo de reflexión.}

a. Doctora en Derecho por la Universidad Autónoma de Querétaro, México. Profesora e investigadora de tiempo completo de la Facultad de Derecho (UAQ), con Reconocimiento Perfil Deseable PRODEP, integrante del Cuerpo Académico Consolidado "Derechos humanos y globalización" Facultad de Derecho (UAQ), miembro del Sistema Nacional de Investigadores del Consejo Nacional de Ciencia y Tecnología. ORCID: https://orcid.org/0000-0003-3733-6459

Para citar este artículo: Aguado, G. (2019). Derecho natural de asociación en la figura de la coalición electoral en México. Revista Misión Jurídica, 12, (16), $197-211$. 
asociación o de reunión no se puede coartar, se analiza que ciertas variantes determinadas en la figura de la coalición ofrecen ventajas y desventajas, pues sus límites y conciliación con otros derechos conlleva a oportunos señalamientos.

\section{PALABRAS CLAVE}

Derecho natural, asociación, coalición, política.

\section{RESUMO}

A associação como direito natural, e colocada em prática como direito político eleitoral, é o ponto em que os cidadãos e o Estado se articulam, pois permite que indivíduos autorizados participem e intervenham nos assuntos políticos do país e alcançar objetivos comuns por uma união de forças. 0 direito de associação em questões político eleitoral vem evoluindo como um direito natural de conteúdo progressista, mas o objetivo de associar-se a questões políticas é a proteção de direitos e a resistência à opressão, mesmo quando se reconhece que o direito de associação ou reunião não pode ser reduzido, analisa-se que certas variantes determinadas na figura da coligação oferecer vantagens e desvantagens porque os seus limites e conciliação com outros direitos levam a observações oportunas.

\section{PALAVRAS-CHAVE}

Direito natural, associação, coligação, política.

\section{ABSTRACT}

The association as a natural right, when put into practice as a political-electoral right is the stage in which the citizens and the State connect with each other because it allows the individuals autorized to do so to participate and intervene in the political affairs of the country and to achieve common goals by joining forces. The right to association in political-electoral matters has been evolving as a natural right of progressive content 4 , the aim of associating in political matters is for the protection of rights and to resist oppression. Nevertheless, even when it is known that the right to associate or to assembly can not be restricted it is observed that certain variants that are determined in the figure of coalition offer advantages and disadvantages since their limits and conciliation with other rights lead to appropriate remarks.

\section{KEY WORDS}

Natural right; association; coalition; politics.

\section{INTRODUCCIÓN}

El objetivo principal de la presente investigación es evidenciar mediante un estudio analítico, que la forma en la que se encuentra regulado el derecho de asociación y reunión en México, da lugar a que el derecho de asociación en materia política, y en específico, en la figura de la coalición se preste a confusiones, ya que al no ofrecer una clara delimitación, se tienen considerables desventajas consecuencia del ejercicio del mismo, pues al no considerar sus límites y conciliación con otros derechos, conlleva a contradicciones y por lo tanto se desvirtúa la finalidad del ejercicio del derecho humano de asociación, que en materia política tiene como fin la protección de derechos y resistencia a la opresión, así como lograr fines comunes a partir de la unión de fuerzas. Las formas más elaboradas de asociación del ser humano, siempre requerirán de una mayor delimitación de la manera en que son puestas en práctica y por tanto, será siempre necesario establecer un ordenamiento jurídico como elemento indispensable en un Estado de Derecho, si queremos justificar su existencia conforme al derecho natural, solo basta recordar que el hombre naturalmente usa su razón y la plasma formalmente en una norma como una figura de protección para prevenir futuras conductas contrarias al objetivo que busca alcanzar.

La figura de la asociación tiene su fundamento en el derecho natural, ya que la propia experiencia del ser humano le ha llevado a distinguir el resultado de un trabajo individual al de un trabajo colectivo; la razón, como la capacidad humana para establecer relaciones entre ideas y hechos, da lugar a que el hombre busque agruparse con sus semejantes para alcanzar sus objetivos propuestos. Esta figura establecida en la norma como una libertad subjetiva pública conocida como "el derecho de asociación", se protege sin más limitaciones que las que le impone el propio orden social.

Para efectos de contextualizar el presente trabajo, mencionaremos los principales instrumentos dentro de los cuales se reconoce el derecho en estudio. Para realizar lo anterior, partiremos del ámbito de reconocimiento internacional de carácter universal, posteriormente el ámbito de reconocimiento regional y por último el ámbito nacional. 
A nivel internacional, encontramos diversos instrumentos universales que reconocen el derecho de asociación:

Declaración Universal de los Derechos Humanos de 1948: "1. Toda persona tiene derecho a la libertad de reunión y de asociación pacíficas".

Pacto Internacional de los Derechos Civiles y Políticos lo dispone en el artículo 21, al establecer que "...toda persona tiene derecho a asociarse libremente con otras, incluso el derecho a fundar sindicatos y afiliarse a ellos para la protección de sus intereses".

Dentro del ámbito regional, encontramos los siguientes instrumentos:

La Declaración Americana de los Derechos del Hombre de 1948 que, en su artículo XXII, dispone que "toda persona tiene el derecho de asociarse con otras para promover, ejercer y proteger sus intereses legítimos de orden político, económico, religioso, social, cultural, profesional, sindical o de cualquier otro orden".

La Convención Americana sobre Derechos Humanos suscrita en la Conferencia Especializada Interamericana sobre Derechos Humanos, celebrada en 1969 en San José, Costa Rica, señala en su artículo 16, numeral 1, que: "Todas las personas tienen derecho a asociarse libremente con fines ideológicos, religiosos, políticos, económicos, laborales, sociales, culturales, deportivos o de cualquier otra índole."

En México, este derecho ha sido reconocido por nuestro ordenamiento nacional a partir de la Constitución de 1857, que lo disponía de la siguiente manera: "Articulo 9.- A nadie se le puede coartar el derecho de asociarse o de reunirse pacíficamente con cualquier objeto lícito; pero solamente los ciudadanos de la República pueden hacerlo para tomar parte en los asuntos políticos del país" (Suárez y Jiménez, 1994: 25).

Posteriormente, fue consagrado en la Constitución de $1917^{2}$, quedando previsto (dentro del mismo numeral), primero como garantía

2. Cabe señalar que desde la publicación de la Constitución de 1917, dicho artículo ha formado parte de los 22 artículos que no han sufrido reforma alguna hasta la fecha. Información obtenida de: http://www.diputados.gob.mx/LevesBiblio/ref/cpeum art.htm individual y actualmente como derecho humano. A partir de la reforma en materia de derechos humanos del 10 de junio de 2011, el alcance del derecho de asociación se amplía a las personas (como genero), quedando comprendidas con esto, tanto a las personas físicas como a las personas jurídico colectivas.

Por otro lado y desde un marco político electoral podemos decir que el derecho de asociación se encuentra regulado actualmente en la Ley General de Partidos Políticos y la Ley General de Instituciones y Procedimientos Electorales, sin embargo, su antecedente más remoto, lo encontramos en la Ley Federal de Organizaciones Políticas y Procesos Electorales de 1977, que definía a las asociaciones políticas como: "formas de agrupaciones políticas, susceptibles de transformarse conjunta o separadamente en partidos políticos, que contribuyen al desarrollo de una opinión política mejor informada y con mayor densidad ideológica".

Una vez contextualizado el marco normativo del derecho de asociación, lo analizaremos a partir del derecho natural, para posteriormente reconstruir su aplicación político electoral, a partir de la figura de las agrupaciones o asociaciones políticas nacionales. Realizaremos una breve revisión del ordenamiento jurídico mexicano que prevé el derecho político a las coaliciones electorales, realizando un análisis de su definición y poniendo a discusión los principios políticos y filosóficos de la asociación como un derecho natural; por último, señalaremos las ventajas y desventajas de estas variantes del derecho de asociación.

Este análisis pretende reflexionar sobre el derecho de asociación y la coalición como una figura social y política, además de exponer resultados de investigación desde una perspectiva analítica, interpretativa y crítica.

\section{DERECHO NATURAL DE ASOCIACIÓN}

El hombre ha desarrollado la figura de la asociación desde su propia naturaleza humana, la racionalidad obliga a entender que necesitamos de los demás para sobrevivir y la asociación es una manifestación de la necesidad humana a la vida social, a la coordinación y a la cooperación. Ya Aristóteles, citado por Amadeo, decía que 
(...) el hombre es un ser sociable por naturaleza... La vida social es un imperioso mandato de la naturaleza. El primero que fundó una asociación pacífica hizo a la humanidad el mayor de los beneficios; porque si el hombre, perfeccionado por la sociedad, es el primero de los animales, es también el último cuando vive sin leyes y sin justicia, (Amadeo, 1922: 21).

De manera muy general podemos afirmar que se da la asociación siempre que un número de personas se unen jurídicamente para un fin común, pues asociarse no significa otra cosa que juntarse para lograr un resultado que de manera individual es imposible o más complicado alcanzarlo. Siendo la asociación, una institución natural que sirve al hombre para complementarse, pues la propia individualidad del ser humano le impide alcanzar objetivos y metas que se vuelven más viables y posibles en el momento en que se da una cooperación de fuerzas, que solo se logra por la unión y la conformación de un conjunto de seres humanos.

La disposición a la vida social, característica de la parte espiritual del hombre, facilita la agrupación, ya que la propia historia del hombre desde sus inicios nos demuestra que es un medio para superar sus posibilidades individuales frente a la ambición de concretar proyectos más complejos de progreso espiritual y material, logrando así llevar a cabo sus mayores empresas.

Podemos señalar a la familia como la primera agrupación (que se reconoce desde la prehistoria como el clan). De esta primera estructura social, habrán de derivarse otros tipos de asociación, diversas en concordancia con sus fines.

La asociación constituye, pues, un resorte del dinamismo de los seres humanos en su camino incesante hacia el progreso, en ese avance constante, la humanidad sigue hasta la implantación de sus ideales; pero es, al mismo tiempo, un fenómeno que aparece en provecho del individuo, un medio natural destinado a protegerlo y desarrollarlo (Núñez, 2011: 52).

Los resultados, consecuencia de la asociación, son los que motivan al hombre a continuar fomentándola, pues consigue resultados que de otro modo serían irrealizables o también su propia experiencia le demuestra que puede alcanzar resultados con mayor facilidad $y$ eficacia, pues aun en cuestiones tan sencillas como levantar una roca, pudo experimentar que las fuerzas unidas de varios hombres dan un resultado mayor que la fuerza singular, $\mathrm{y}$ en algunos casos muchos fines no pueden alcanzarse sin la combinación de las fuerzas.

El hombre se encontró con que su fin individual no necesariamente era ajeno o diverso al de otros hombres, al socializar comprobó que la asociación despliega una actividad más sencilla y más fuerte en la consecución de fines comunes, por esto se le concede gran importancia al fenoméno asociativo y justifican su importancia como instrumento natural de colaboración en las actividades, conjugando inteligencias en la consecución de fines.

Sin embargo, estas asociaciones han tomado diversas formas y se han hecho tan complejas como el propio ser humano ha necesitado conformarlas.

A continuación, revisaremos algunas variantes de las formas de asociación o agrupaciones políticas nacionales y su alcance políticoelectoral. Estas organizaciones buscan a través de la asociación mejorar y defender las condiciones de los grupos que tienen diversas tendencias políticas o ideológicas, situación necesaria para la democracia de un país y el fortalecimiento de la sociedad. Las manifestaciones más conocidas del fenómeno asociativo son los partidos políticos, sin embargo, previo a su estudio revisaremos lo que son las agrupaciones políticas nacionales.

\section{AGRUPACIONES POLÍTICAS NACIONALES}

En materia político-electoral, la antesala de los partidos políticos son las agrupaciones políticas nacionales, de lo cual, surge el siguiente cuestionamiento ¿qué es una agrupación política?, para responder esta pregunta, revisamos el artículo 20 de la Ley General de Partidos Políticos que a la letra dispone: "Las agrupaciones políticas nacionales son formas de asociación ciudadana que coadyuvan al desarrollo de la vida democrática y de la cultura política, así como la creación de una opinión pública mejor informada." Luego entonces podemos afirmar que estás se presentan como una primer forma de asociación de los individuos, en ejercicio de una ciudadanía que los identifica y los lleva a conformar agrupaciones. 
Las agrupaciones políticas nacionales no pueden utilizar las denominaciones de "partido o partido político", pues como comentamos con antelación son una primer forma de asociación entre ciudadadanos que tienen fines políticos, pero que solo podrán participar en procesos electorales federales, mediante acuerdos de participación con un partido político o coalición.

\section{PARTIDOS POLÍTICOS}

Previo a comenzar con el estudio de las coaliciones electorales, es menester saber qué es un partido político, ya que su definición tiene cierta influencia en el concepto de coalición política, como así lo dispone el artículo 21 de la citada ley: "Los partidos políticos y las asociaciones políticas nacionales podrán confederarse, aliarse o unirse con el fin de constituir coaliciones o frentes", podemos ver que una forma de asociación se potencializa cuando crea nuevas uniones, buscando conforme al derecho natural alcanzar mayor fortaleza.

Gómez, piensa a la sociedad civil como el lugar en donde se hacen presentes y se desarrollan los conflictos económicos, sociales, ideológicos o religiosos que las instituciones estatales tienen la misión de resolver, la sociedad civil como grupo contrapuesto al Estado esta conformada por clases sociales o por agrupaciones, asociaciones y organizaciones que las representan, junto con los movimientos de clase y grupos de interés, sin embargo, los partidos políticos tienen un pie en la sociedad civil y otro en las instituciones, pues no pertenecen del todo a la sociedad civil ni al Estado (Gómez, 2013:44).

La definición del concepto estudiado, la podemos encontrar dentro, del artículo $3^{\circ}$ de la Ley General de Partidos Políticos, que a la letra dispone:

Los partidos políticos son entidades de interés público con personalidad jurídica y patrimonio propios, con registro legal ante el Instituto Nacional Electoral o ante los Organismos Públicos Locales, y tienen como fin promover la participación del pueblo en la vida democrática, contribuir a la integración de los órganos de representación política y, como organizaciones de ciudadanos, hacer posible el acceso de éstos al ejercicio del poder público (Congreso General de los Estados Unidos Mexicanos, 2015).
Para analizar el artículo mencionado, lo dividiremos en dos partes. En primer lugar, podemos observar que la ley refiere a los partidos políticos como “(...) entidades de interés público con personalidad jurídica y patrimonio propios, con registro legal ante el Instituto Nacional Electoral o ante los Órganos Públicos Locales (...)". Este enunciado lo analizaremos desde tres puntos de vista:

- Los partidos políticos se ven como entidades de una colectividad considerada como una unidad, teniendo un interés en el bien común de la sociedad.

- Cuentan con la capacidad suficiente para hacer valer sus derechos y contraer obligaciones, generándose a través de actividades que requieren de determinada responsabilidad jurídica para su aplicación.

- Son propietarios y administradores de sus bienes inmuebles que son indispensables para el cumplimiento de sus fines y que estén debidamente inscritos ante el Instituto Nacional Electoral (en adelante INE).

La segunda parte a analizar, es la referente al fin que persiguen: "[...] tienen como fin promover la participación del pueblo en la vida democrática, contribuir a la integración de los órganos de representación política $\mathrm{y}$, como organizaciones de ciudadanos, hacer posible el acceso de éstos al ejercicio del poder público.", esta parte refiere a los objetivos que persiguen los partidos políticos, dividiéndose para su análisis, en tres fines los cuales son:

- El promover la participación del pueblo en la vida democrática ayuda a tener una organización social más eficaz y productiva, para llegar a una cultura de paz y prosperidad

- Contribuir a la integración de los órganos de representación política a nivel, local, estatal y federal, estos puestos de representación son: diputados, senadores, presidentes municipales, gobernadores de Estados, presidente de la República, etc.

- El acceso de los ciudadanos a los órganos de representación política, como un derecho de los ciudadanos a votar en las elecciones po- 
pulares, y poder ser votados para todos los cargos de elección popular ${ }^{3}$, sin distinción de sexo, raza, religión o ideas, esto en razón del principio de no discriminación que prevé el último párrafo del artículo $1^{\circ}$ constitucional.

Para entrar al estudio de las coaliciones electorales, habremos de observar que actualmente en nuestro país, los partidos políticos han visto la necesidad de sumar esfuerzos con otros partidos. Como lo revisamos en el apartado "Derecho natural de asociación", es la manera más viable de alcanzar uno de los fines antes mencionados, es decir, el acceso al poder ${ }^{4}$.

\section{COALICIONES ELECTORALES}

Podemos referir que la coalición electoral es una figura jurídica en materia electoral, que se crea a través de un convenio celebrado entre partidos políticos, cuando se asocian varios partidos políticos que tienen un interés público, político, jurídico y social en común, regulados por la Ley General de Partidos Políticos y la Ley General de Instituciones y Procedimientos Electorales.

Los partidos políticos podrán confederarse, aliarse o unirse con el fin de constituir coaliciones o frentes, como así lo establece el artículo 85 de la Ley General de Partidos Políticos, al establecer que:

(...) los partidos políticos podrán constituir frentes, para alcanzar objetivos políticos y sociales compartidos de índole no electoral, mediante acciones y estrategias específicas y comunes.

Los partidos y asociaciones que formen parte conservan su personalidad jurídica, registro e identidad; mientras que las coaliciones, se constituyen con fines electorales y tienen por objeto postular los mismos candidatos en las elecciones de presidente, senadores y de diputados de mayoría relativa y de representación proporcional.

De lo anterior, nos surge la siguiente interrogante ¿Cuál es la diferencia entre coalición y frente?, la diferencia entre uno y otro, radica

3. Al respecto, remítase al artículo 35 fracción I y II de la Constitución Política de los Estados Unidos Mexicanos.

4. Para revisar la historia del marco jurídico de los partidos políticos en México, ver investigación de Corona, 2016. en que el derecho de asociación del "frente" no es para alcanzar un fin electoral, mientras que para la "coalición ", su derecho de asociación si se ejerce con ese objetivo.

Por su parte, el artículo 87 de la multicitada ley, prevé la figura de la coalición en los siguientes términos:

1. Los partidos políticos nacionales podrán formar coaliciones para las elecciones de presidente de los Estados Unidos Mexicanos, así como de senadores y de diputados por el principio de mayoría relativa.

2. Los partidos políticos nacionales y locales podrán formar coaliciones para las elecciones de Gobernador, diputados a las legislaturas locales de mayoría relativa y ayuntamientos, así como de Jefe de Gobierno, diputados a la Asamblea Legislativa de mayoría relativa y los titulares de los órganos políticoadministrativos de las demarcaciones territoriales del Distrito Federal.

Como podemos ver las formas más elaboradas de asociación del ser humano, siempre darán lugar a una mayor delimitación de la manera en que son puestas en práctica y por tanto será siempre necesario establecer un ordenamiento jurídico como elemento indispensable en un Estado de Derecho, para efectos de la coalición esto se prevé en el artículo 12, párrafo segundo de la Ley General de Instituciones y Procedimientos Electorales:

El derecho de asociación de los partidos políticos en los procesos electorales a cargos de elección popular federal o local estará regulado por la Ley General de Partidos Políticos. Independientemente del tipo de elección, convenio de coalición y términos precisados en el mismo, cada uno de los partidos políticos aparecerá con su propio emblema en la boleta electoral, según la elección de que se trate; los votos se sumarán para el candidato de la coalición y contarán para cada uno de los partidos políticos para todos los efectos establecidos en esta Ley. En ningún caso se podrá transferir o distribuir votación mediante convenio de coalición (Congreso General de los Estados Unidos Mexicanos, 2014).

Ordenamientos secuenciales y delimitativos cada uno de los mencionados con anterioridad, que, para justificar su existencia conforme al 
derecho natural, solo basta recordar que el hombre naturalmente usa su razón y la plasma formalmente en una norma como una forma de protección para prevenir futuras conductas contrarias al objetivo que busca alcanzar.

Para que se forme una alianza preelectoral deben darse determinadas condiciones. La denominada hipótesis de la desproporcionalidad sostiene que es más probable que las alianzas surjan en los sistemas electorales desproporcionales si existen más de dos partidos políticos. El supuesto básico es que el sistema electoral tiene un considerable efecto en la formación de coaliciones y alianzas en el periodo preelectoral.

Los sistemas electorales de mayoría/ pluralidad, generalmente conceden ventajas a los partidos más grandes. Si contienden más de dos partidos, los más grandes tienden a buscar alianzas preelectorales para incrementar sus oportunidades de lograr la mayoría de los escaños. En este tipo de sistemas electorales, los partidos pueden, por ejemplo, compartir sus votos o incluso, transferirlos de manera sistemática como parte de su alianza electoral.

Otro enfoque para explicar la formación de alianzas preelectorales es el que se sustenta en la denominada teoría del mecanismo de señales. La formación de coaliciones previas a las elecciones se interpreta como una señal o demostración clara al electorado de que el partido será capaz de gobernar al país bajo una coalición estable. Esto puede ser especialmente válido en situaciones donde los partidos opositores forman grandes coaliciones contra el partido gobernante. Si un gran partido ha gobernado por mucho tiempo, es posible que los partidos opositores traten de acercar sus posiciones para formar una alianza a fin de sustituir al gobierno ${ }^{5}$. Sin embargo, no debemos confundir las coaliciones preelectorales con los gobiernos de coalición, ambos refieren una variante del derecho de asociación, pero la finalidad de cada uno, es distinta.

Las reglas que se aplican a la figura de la coalición, se prevén en el artículo 87 de la Ley

5. ACE Red de Conocimientos Electorales, "Partidos y candidatos, Partidos y candidatos en el proceso electoral, Coaliciones y alianzas electorales", consultado en página web el 25 de julio de 2018, disponible en: http://aceproject.org/ace-es/topics/pc/default
General de Partidos Políticos y son las que a continuación se señalan:

1. Presentar solicitud de registro al presidente del organismo público local, previa acreditación del órgano de dirección nacional de cada uno de los partidos coaligados. Acompañando el programa de gobierno de la coalición o de uno de los partidos coaligados, conforme a los estatutos de cada uno de los partidos.

2. Solo se formarán coaliciones entre los partidos políticos nacionales para elecciones de presidente de los Estados Unidos Mexicanos, senadores, y diputados por el principio de mayoría relativa.

3. Los partidos políticos nacionales y locales podrán formar coalición para la elección de las autoridades a nivel local.

4. Los partidos políticos no podrán postular candidatos propios donde ya hubiere candidatos de la coalición de la que ellos formen parte. Esto quiere decir que los partidos políticos no podrán imponer a sus candidatos a un puesto de elección de mayoría relativa, cuando ya hay un candidato elegido por la coalición, en que ese partido político ya forma parte.

5. Ningún partido político podrá registrar como candidato propio a alguien que ya ha sido registrado como candidato de alguna otra coalición. De igual manera no podrá ninguna coalición postular como candidato de la coalición a alguien que ya esté registrado como candidato de algún otro partido político.

6. No se podrá registrar a algún candidato de otro partido político, claro excepto que este candidato forme parte de la coalición.

7. Todos los partidos políticos que se coaliguen o que quieren formar una coalición para elecciones, tendrán que celebrar un convenio respectivo. Dicha celebración de convenio se podrá hacer entre dos o más partidos políticos.

8. Solo se podrá celebrar una coalición en un mismo proceso electoral, ya sea local o federal, y la coalición que se forme de esta debe 
ser uniforme ${ }^{6}$.

9. Los partidos políticos no podrán distribuirse o transferirse votos mediante convenio de coalición ${ }^{7}$.

10. Al finalizar la etapa de resultados de las elecciones de senadores y diputados, se terminará automáticamente la coalición por la que se hayan postulado los candidatos, en el caso de resultar electos los candidatos de la coalición, estos quedarán comprendidos en el partido político en el que se haya señalado dentro del convenio de coalición.

11. Independientemente del tipo de elección, convenio y términos en que los partidos coaligados se comprometieron, cada uno de ellos aparecerá con su propio emblema en la boleta electoral, según la elección de que se trate; los votos se sumarán para el candidato de la coalición y contarán para cada uno de los partidos políticos. Y dichos votos en los que se hubiesen marcado más de una opción de los partidos que tienen una coalición, estos votos serán considerados válidos para el candidato postulado por la coalición y solo contarán como un solo voto.

Existen distintos alcances de la coalición electoral, pues puede haber coaliciones totales, coaliciones parciales o coaliciones flexibles. Alcances de coalición que se dan en razón del porcentaje de candidatos que se postulan a puestos de elección popular por los partidos políticos, coaligados en un mismo proceso electoral. A continuación, realizaremos el estudio de las características de cada una de las variables mencionadas, para lo cual, dentro de cada una de ellas, analizaremos la parte que refiere a las mismas dentro del articulo 88 de la Ley General de los Partidos Políticos:

1. Totales: "Se entiende como coalición total, aquella en la que los partidos políticos

6. Esto quiere decir que ningún partido político podrá estar en más de una coalición y dicha coalición no podrá ser diferente en los propósitos y de lo que hacen los partidos políticos que las integran.

7. Cabe enfatizar esta parte ya que puede resultar algo ambigua, la no distribución de los votos de una coalición, atiende a que no se podrán transferir o distribuir votos de una elección local para presidente municipal a los votos que hayan tenido por una elección para presidente de los Estados Unidos Mexicanos, o para senadores, o diputados a nivel federal. coaligados postulan en un mismo proceso federal o local, a la totalidad de sus candidatos a puestos de elección popular bajo una misma plataforma electoral".

De lo anterior podemos observar, que existe una regla específica cuando se trata de coaliciones totales, esa regla se refiere a que, si dos o más partidos se coaligan en forma total para las elecciones de senadores o diputados, deberán coaligarse para la elección de presidente de los Estados Unidos Mexicanos. En el caso de las elecciones locales si dos o más partidos se coaligan en forma total para las elecciones de diputados locales o de diputados a la Asamblea Legislativa, deberán coaligarse para la elección de Gobernador o Jefe de Gobierno.

2. Parciales: "Coalición parcial es aquella en la que los partidos políticos coaligados postulan en un mismo proceso federal o local, al menos al cincuenta por ciento de sus candidatos a puestos de elección popular bajo una misma plataforma electoral". No lo están arriesgando todo sino solo comparten la mitad de los candidatos, se reparten las postulaciones por mitad.

3. Flexibles: Se entiende como coalición flexible, "aquella en la que los partidos políticos coaligados postulan en un mismo proceso electoral federal o local, al menos a un veinticinco por cierto de candidatos a puestos de elección popular bajo una misma plataforma electoral." Este tipo de coaliciones poseen una mecánica que permite a los partidos políticos que la integran, delimitar un número específico de cargos, teniendo como regla al menos un $25 \%$ de los postulados a elección popular.

En relación con el alcance de la coalición podemos referir que esto tiene importantes implicaciones para el desarrollo de la elección, pues entre otras cosas trascendentales para obtener el triunfo, esto impacta en el uso de los tiempos en radio y televisión, así como el financiamiento de la elección como medios para exponer sus candidaturas al electorado, y la manera en la que votan los electores.

Para entender mejor los alcances de las coaliciones totales, parciales o flexibles, se presenta la siguiente tabla que refleja numéricamente el mínimo de candidaturas a cargos de elección popular que deberán presentar los partidos políticos según el alcance de la coalición. 
Tabla 1. Número mínimo de candidaturas según el alcance de la coalición

\begin{tabular}{|c|c|c|c|}
\hline \multirow{2}{*}{ Coalición } & \multicolumn{3}{|c|}{ Número mínimo de candidaturas que deberán presentar según alcance de la coalición } \\
\cline { 2 - 4 } & Presidencia & Senadurías & Diputaciones \\
\hline Total & 1 & 64 & 300 \\
\hline Parcial & 0 ó 1 & 32 & 150 \\
\hline Flexible & 0 ó 1 & 16 & 75 \\
\hline
\end{tabular}

Fuente: Huffpost, 2018

En razón de lo anterior, podemos observar que los partidos podrán establecer una distribución dinámica en la conformación de la coalición, siempre y cuando se garantice la uniformidad de los integrantes en dicho convenio, en el entendido de que, si converge alguna coalición total de diputados y/o senadores, necesariamente deben de contemplar la elección de presidente de la República (Huffpost, 2018).

Los requisitos que han de contener los convenios de coalición, previstos en el artículo 91 de la Ley General de Partidos Políticos, son los siguientes:

- Deberán de especificar el nombre de los partidos políticos que conformarán la coalición.

- Deberán de determinar en qué proceso electoral participará la coalición, federal o local, o especificar si es en ambas.

- El procedimiento que deberá seguir cada partido político para la selección de los candidatos que serán postulados por la coalición.

- Se deberá acompañar la plataforma electoral y en su caso, el programa de gobierno que sostendrá su candidato a presidente de la República.

- El señalamiento del partido político al que pertenece originalmente cada uno de los candidatos registrados por la coalición.

- Y por último qué mecanismo utilizarán para el caso de la interposición de los medios de impugnación, y quién será el que ostente la representación de la coalición.

Ventajas de las coaliciones electorales

- Los partidos pueden mitigar las debilidades entre sí y beneficiarse de las fortalezas de sus aliados.

- Los partidos pueden aumentar su número de votantes.

- Al combinar fuerzas, los partidos pueden aumentar su influencia.
- Los partidos pueden ampliar su participación en el Congreso. (Red Innovación, 2018)

\section{Desventajas de las coaliciones electorales}

- Cada partido debe hacer concesiones en sus prioridades y ceder algo de control.

- Los partidos pierden cierto control en la toma de decisiones.

- La necesidad de consenso hace que la toma de decisiones sea más lenta.

- Las grandes coaliciones pueden marginar a los grupos de oposición. (Red Innovación, 2018)

Otra desventaja que se puede observar, es que los partidos políticos en su intención de coaligarse, asignan en proporción de la representatividad de cada partido, el porcentaje de los candidatos que han de postular, conforme a los acuerdos previos entre partidos, sin embargo, una vez que la coalición obtiene el triunfo en las elecciones, un partido político más que fortalecido, habrá de compartir el poder con los candidatos electos que ocuparán las posiciones legislativas. Por lo cual, al conformar las coaliciones, es muy complejo que los partidos políticos lleguen a acuerdos al asignar las posiciones legislativas y como referimos anteriormente, la toma de decisiones se vuelve más lenta.

Aún con las desventajas mencionadas, pesa más la ventaja de que la coalición, es una forma de asociación que le brinda a los partidos políticos una oportunidad de tener mejores resultados electorales, pues del convenio de coalición, los partidos pueden lograr una mayor representación con alianzas preelectorales que incrementan sus oportunidades de lograr la mayoría de los escaños. Por lo anterior, no es de extrañar que esta figura haya sido tan utilizada en los últimos comicios electorales en nuestro país. 
Una vez que hemos analizado la definición, condiciones, requisitos, alcances, ventajas y desventajas de la coalición electoral, pasaremos a revisar, históricamente, cuáles son los partidos políticos que han llevado a cabo una coalición en nuestro país.

\section{PARTIDOS POLÍTICOS EN COALICIÓN}

De acuerdo con el Instituto Nacional Electoral (en adelante $\mathrm{INE}^{8}$ ), se presenta la siguiente información sobre los convenios de coalición (de1999 a 2015) celebrados por partidos políticos, para efectos de participar en los procesos electorales federales ${ }^{9}$.

Convenios de coalición 2000, 2003 y 2006 :

- Proceso 1999-2000 -Alianza por México-

- Proceso 1999 - 2000 -- Alianza por el Cambio -

- Proceso 2003 Elecciones Extraordinarias -Alianza para Todos-

- Proceso 2003 -- Alianza para Todos -

- Proceso 2005 - 2006 -- Por el Bien de Todos -

- Proceso 2005 - 2006 -- Alianza por México -

Convenios de coalición 2008 - 2009:

- "Primero México" (PRI, PV).

- "Salvemos a México" (PT, Convergencia)

Convenios de coalición 2011-2012:

- "Compromiso por México" (PRI, PVEM) clausulado integral.

- "Compromiso por México" (PRI, PVEM, Nueva Alianza).

- “Compromiso por México" (PRI, PVEM).

- "Movimiento Progresista" (PRD, PT y Movimiento Ciudadano).

Convenios de coalición 2014-2015:

- Elecciones Extraordinarias, Convenio de Coalición (PAN-Nueva Alianza).

- Elecciones Extraordinarias, Convenio de Coalición (PRI-PVEM).

- Convenio de Coalición Parcial (PRI-PVEM) Definitivo.

- Convenio de Coalición Parcial (PRI-PVEM), clausulado integral.

8. Cabe señalar que previo a la reforma política-electoral de 2014, dicho instituto tenía el nombre de Instituto Federal Electoral.

9. INSTITUTO NACIONAL ELECTORAL, "Convenios de Coalición", consultado en página web el 24 de junio de 2018, disponible en: http://portalanteriorine.mx/archivos3/portal/historico/ contenido/Convenios de coalicion/
- Convenio de Coalición Parcial (PRI-PVEM).

- Convenio de Coalición Flexible "Izquierda Progresista" (PRD-PT) Definitivo.

- Convenio de Coalición Flexible "Izquierda Progresista" (PRD-PT).

Convenios de coalición 2018-2019

- Coalición Por México Al Frente (PAN, PRD, MC).

- Juntos Haremos Historia (PT, MORENA, ENCUENTRO SOCIAL).

- Todos Por México (PRI, PVEM, Nueva Alianza).

De acuerdo con la información anterior podemos observar que los partidos políticos se encontraban formando parte de alguna coalición desde el proceso electoral de 1999-2000, en el cual participaron "Alianza por el Cambio", conformaba por el Partido Acción Nacional (PAN) y el Partido Verde Ecologista de México (PVEM); y "Alianza por México", conformada por el Partido de la Revolución Democrática (PRD), por el Partido del Trabajo (PT), Convergencia por la Democracia (convergencia), Partido Alianza Social (PAS) y Partido de la Sociedad Nacionalista (PSN).

En ocasiones, las coaliciones se hacen llamar "alianzas", por ejemplo, durante el proceso electoral 1999-2000, hubo dos coaliciones políticas, las cuales utilizaron dicha denominación.

No debemos confundir alianza con coalición, ya que la denominación "alianza" solo es el nombre que se les da a las coaliciones, pero no se trata de una figura jurídica independiente a una coalición electoral. Actualmente ni la Constitución, ni la Ley General de Partidos Políticos, ni la Ley General de Instituciones y Procedimientos Electorales, manejan la figura de alianza electoral, por lo tanto, dentro del presente trabajo, solo se utilizará el término "coalición electoral". Y tampoco existe fundamento legal que hubiese estado vigente en 1999 que dispusiera la figura de la alianza electoral.

A continuación, se presenta una tabla en donde se muestran tres aspectos: Aquellos partidos políticos que formaron una coalición (a nivel federal) para participar en los procesos electorales desde 1999 hasta la fecha; el alcance de coalición que formaron (total, parcial o flexible) $y$; la finalidad de dichas colaciones. 
Tabla 2. Partidos políticos en coalición para los procesos federales electorales de 1999 a 2015

\begin{tabular}{|c|c|c|c|c|}
\hline Años & $\begin{array}{l}\text { Denomina- } \\
\text { ción de la } \\
\text { coalición } \\
\end{array}$ & $\begin{array}{l}\text { Partidos } \\
\text { políticos }\end{array}$ & $\begin{array}{l}\text { Alcance de } \\
\text { la coali- } \\
\text { ción }\end{array}$ & Finalidad de la coalición. \\
\hline \multirow[b]{2}{*}{$\begin{array}{c}1999 \\
-2000\end{array}$} & $\begin{array}{l}\text { Alianza Por } \\
\text { El Cambio }\end{array}$ & $\begin{array}{l}\text { PAN y } \\
\text { PVEM }\end{array}$ & Total & $\begin{array}{l}\text { Convenio de coalición para la elección de Presidente } \\
\text { de los Estados Unidos Mexicanos. }\end{array}$ \\
\hline & $\begin{array}{l}\text { Alianza } \\
\text { Por México }\end{array}$ & $\begin{array}{l}\text { PRD, PT, } \\
\text { Conver- } \\
\text { gencia, } \\
\text { PAS y PSN } \\
\end{array}$ & Total & $\begin{array}{l}\text { Convenio de coalición electoral para la elección de } \\
\text { Presidente de los Estados Unidos Mexicanos, de di- } \\
\text { putados y de senadores de mayoría relativa y de re- } \\
\text { presentación proporcional. }\end{array}$ \\
\hline 2003 & $\begin{array}{l}\text { Alianza Para } \\
\text { Todos }\end{array}$ & $\begin{array}{l}\text { PRI y } \\
\text { PVEM }\end{array}$ & $\begin{array}{l}\text { Parcial: } 97 \\
\text { distritos }\end{array}$ & $\begin{array}{l}\text { Convenio de coalición con la finalidad de postular } 97 \\
\text { fórmulas de candidaturas a cargos de diputados fe- } \\
\text { derales por el principio de mayoría relativa. }\end{array}$ \\
\hline \multirow[b]{2}{*}{$\begin{array}{l}2005- \\
2006\end{array}$} & $\begin{array}{l}\text { Coalición } \\
\text { Por El Bien } \\
\text { De Todos }\end{array}$ & $\begin{array}{l}\text { PRD, PT } \\
\text { y Conver- } \\
\text { gencia }\end{array}$ & Total & $\begin{array}{l}\text { Convenio de coalición electoral para la elección de } \\
\text { Presidente de los Estados Unidos Mexicanos, de di- } \\
\text { putados y de senadores de mayoría relativa y de re- } \\
\text { presentación proporcional. }\end{array}$ \\
\hline & $\begin{array}{l}\text { Alianza Por } \\
\text { México }\end{array}$ & $\begin{array}{l}\text { PRI y } \\
\text { PVEM }\end{array}$ & Total & $\begin{array}{l}\text { Convenio de coalición total con la finalidad de postular } \\
\text { candidato a Presidente de la República, } 200 \text { fórmulas } \\
\text { de candidatos a diputados federales por el principio } \\
\text { de representación proporcional; } 32 \text { fórmulas de can- } \\
\text { didatos a senadores por el principio de representa- } \\
\text { ción proporcional en la circunscripción plurinominal } \\
\text { nacional; } 64 \text { fórmulas de candidatos a senadores por } \\
\text { el principio de mayoría relativa en las } 32 \text { entidades } \\
\text { federativas; y, las fórmulas de candidatos a diputados } \\
\text { por el principio de mayoría relativa en cada uno de los } \\
300 \text { distritos electorales uninominales. }\end{array}$ \\
\hline \multirow{2}{*}{$\begin{array}{c}2008- \\
2009\end{array}$} & $\begin{array}{l}\text { Coalición } \\
\text { Salvemos A } \\
\text { México } \\
\end{array}$ & $\begin{array}{l}\text { PT y Con- } \\
\text { vergencia }\end{array}$ & Total & $\begin{array}{l}\text { Convenio de coalición electoral para la elección de } \\
300 \text { diputados por el principio de mayoría relativa. }\end{array}$ \\
\hline & $\begin{array}{l}\text { Coalición } \\
\text { Primero } \\
\text { México } \\
\end{array}$ & $\begin{array}{l}\text { PRI y } \\
\text { PVEM }\end{array}$ & $\begin{array}{l}\text { Parcial: } 63 \\
\text { distritos }\end{array}$ & $\begin{array}{l}\text { Convenio de coalición con la finalidad de postular } \\
\text { fórmulas de candidatos a diputados por el principio } \\
\text { de mayoría relativa en } 63 \text { de los } 300 \text { distritos. }\end{array}$ \\
\hline \multirow[t]{2}{*}{$\begin{array}{c}2011- \\
2012\end{array}$} & $\begin{array}{l}\text { Compromiso } \\
\text { Por México }\end{array}$ & $\begin{array}{l}\text { PRI, PVEM } \\
\text { y Nueva } \\
\text { Alianza }\end{array}$ & $\begin{array}{l}\text { Parcial } \\
125 \text { distri- } \\
\quad \text { tos }\end{array}$ & $\begin{array}{l}\text { Convenio de coalición con la finalidad de postular } \\
\text { candidato en la elección de Presidente de la Repú- } \\
\text { blica, } 20 \text { fórmulas de candidatos a senadores por el } \\
\text { principio de mayoría relativa, en } 10 \text { de las } 32 \text { entida- } \\
\text { des federativas y fórmulas de candidatos a diputados } \\
\text { por el principio de mayoría relativa en } 125 \text { de los } 300 \\
\text { distritos electorales uninominales. }\end{array}$ \\
\hline & $\begin{array}{l}\text { Movimiento } \\
\text { Progresista }\end{array}$ & $\begin{array}{l}\text { PRD, PT y } \\
\text { MC }\end{array}$ & Total & $\begin{array}{l}\text { Convenio de coalición electoral total que para la elec- } \\
\text { ción de Presidente de la República, fórmulas de can- } \\
\text { didatos a senadores en las } 32 \text { entidades Federativas } \\
\text { y de diputados en los } 300 \text { distritos.electorales, por el } \\
\text { principio de mayoría relativa. }\end{array}$ \\
\hline
\end{tabular}




\begin{tabular}{|c|c|c|c|l|}
\hline $2014-$ & $\begin{array}{c}\text { Izquierda } \\
\text { Progresista }\end{array}$ & PRD y PT & $\begin{array}{c}\text { Flexible } \\
100 \text { distri- } \\
\text { tos }\end{array}$ & $\begin{array}{l}\text { Convenio de coalición electoral para la elección de can- } \\
\text { didatos y candidatas a diputadas y diputados del H. Con- } \\
\text { greso de la unión, por el principio de mayoría relativa. }\end{array}$ \\
\cline { 2 - 5 } 2015 & $\begin{array}{c}\text { COALICIÓN } \\
\text { PRI-PVEM }\end{array}$ & $\begin{array}{c}\text { PRI y } \\
\text { PVEM }\end{array}$ & $\begin{array}{c}\text { Parcial } \\
250 \text { distri- } \\
\text { tos }\end{array}$ & $\begin{array}{l}\text { Convenio de coalición parcial con la finalidad de pos- } \\
\text { tular fórmulas de candidatos a diputados por el prin- } \\
\text { cipio de mayoría relativa en doscientos cincuenta, de } \\
\text { los trescientos distritos electorales uninominales en } \\
\text { que se divide el país. }\end{array}$ \\
\hline
\end{tabular}

Fuente: Tabla elaborada, hasta 2009, por Ernesto Ramos Mega (2011: 26-27) con datos de www.ife.org.mx; desde 2011 a 2018 actualizada por autoría propia con datos de www.ine.mx (INSTITUTO NACIONAL ELECTORAL, 2018)

Como vemos en la tabla anterior, que contiene los partidos que integran las coaliciones, el alcance de estas y su finalidad, antes del proceso electoral 2018, hubo once coaliciones en elecciones ordinarias, de las cuales solo seis fueron para elección de presidente de la República, mientras que 10 tuvieron como finalidad postular fórmulas de candidatos a diputados y cinco para candidatos a senadores.

En la tabla anterior pudimos observar las coaliciones políticas que se formaron para los procesos electorales de 1999 a 2015. A continuación (siguiendo la misma metodología) abordaremos las formadas para el proceso electoral 2018, a nivel federal.

Tabla 3. Partidos políticos en coalición para el proceso federal electoral de 2018

\begin{tabular}{|c|c|c|c|c|}
\hline Año & $\begin{array}{l}\text { Denominación } \\
\text { de la coalición }\end{array}$ & $\begin{array}{l}\text { Partidos } \\
\text { políticos } \\
\text { que la con- } \\
\text { forman }\end{array}$ & $\begin{array}{l}\text { Alcance } \\
\text { de coali- } \\
\text { ción }\end{array}$ & Finalidad de la coalición \\
\hline 2018 & $\begin{array}{l}\text { Coalición Por } \\
\text { México Al Frente }\end{array}$ & $\begin{array}{l}\text { PAN, PRD y } \\
\text { MC }\end{array}$ & $\begin{array}{l}\text { Parcial } \\
150 \text { dis- } \\
\text { tritos }\end{array}$ & $\begin{array}{l}\text { Convenio de coalición con la finalidad de postu- } \\
\text { lar candidatos a Presidente de la República, a se- } \\
\text { nadores en al menos } 16 \text { entidades federativas, y } \\
\text { de diputados federales en al menos } 150 \text { distritos } \\
\text { electorales, por el principio de mayoría relativa. }\end{array}$ \\
\hline 2018 & $\begin{array}{c}\text { Juntos Haremos } \\
\text { Historia }\end{array}$ & $\begin{array}{l}\text { PT, Morena } \\
\text { y PES }\end{array}$ & $\begin{array}{l}\text { Parcial } \\
292 \text { dis- } \\
\text { tritos }\end{array}$ & $\begin{array}{l}\text { Convenio de coalición parcial con la finalidad de } \\
\text { postular candidato de Presidente de la República; } \\
\text { así como para postular fórmulas de candidatos a } \\
\text { diputados por el principio de mayoría relativa en } \\
292 \text { de los } 300 \text { distritos y para postular } 62 \text {, de } 64 \\
\text { fórmulas de candidatos a senadores por el princi- } \\
\text { pio de mayoría relativa. }\end{array}$ \\
\hline 2018 & $\begin{array}{c}\text { Todos Por Mé- } \\
\text { xico }\end{array}$ & $\begin{array}{l}\text { PRI, PVEM } \\
\text { y Nueva } \\
\text { Alianza }\end{array}$ & $\begin{array}{c}\text { Flexible } \\
133 \text { dis- } \\
\text { tritos }\end{array}$ & $\begin{array}{l}\text { Convenio de coalición con la finalidad de postular } \\
\text { candidato a la presidencia de la República; parcial } \\
\text { para } 34 \text { fórmulas de candidatos a senadores por el } \\
\text { principio de mayoría relativa, en } 17 \text { de las } 32 \text { en- } \\
\text { tidades federativas que integran el territorio na- } \\
\text { cional; y flexible para las fórmulas de candidatos } \\
\text { a diputados por el principio de mayoría relativa en } \\
133 \text { de los } 300 \text { distritos electorales uninominales. }\end{array}$ \\
\hline
\end{tabular}

Fuente: Elaboración propia a partir de información obtenida de Instituto Nacional Electoral (2018a, 2018b, 2018c, 2018d). 
Podemos observar, que la coalición "Juntos Haremos Historia", contó con un mayor alcance, pues, aunque fue una coalición parcial, tuvo como finalidad, postular al candidato a la presidencia de la República, a 292 candidatos para diputaciones federales de un total de 300 distritos uninominales por el principio de mayoría y; postuló a 62 de 64 fórmulas de candidatos a senadores por el principio de mayoría relativa. Por otro lado, la "Coalición Por México Al Frente", fue parcial, postuló a un candidato a la presidencia de la República, a candidatos a senadores en 16 entidades federativas por el principio de mayoría relativa y 150 diputaciones federales por el principio de mayoría relativa al Congreso de la Unión. Mientras que la coalición "Todos Por México" fue de tipo flexible, postuló la candidatura a la presidencia de la República, parcial para postular 34 fórmulas de candidatos a senadores por el principio de mayoría relativa en 17 de las 32 entidades federativas y candidatos a diputados por el principio de mayoría relativa en 133 de los 300 distritos electorales uninominales.

Lo anterior tuvo un impacto considerable en la victoria que obtuvo la coalición "Juntos Haremos Historia", pues aunque el elector no estuviera muy convencido de su voto, al marcar (en la boleta electoral) cualquiera de los recuadros en donde figuraba algún candidato de la coalición, el voto marcado de manera indecisa era acumulativo para esta.

Es importante denotar la relación existente entre los resultados electorales de 2018, con el derecho de asociación, pues en dicho proceso, se puede observar que dicho ejercicio fue un factor determinante para lograr el triunfo en la contienda electoral.

A continuación, señalaremos las ventajas y desventajas de los partidos políticos que crean coaliciones $^{10}$ :

\section{Ventajas de los partidos políticos en coalición}

- El sistema de financiamiento y el reparto de spots, generan incentivos favorables en las campañas, se suma el financiamiento de los partidos políticos que forman parte de la coalición.

10. También resultan aplicables las ventajas y desventajas que señalamos en el apartado de "Coaliciones electorales".
- Las coaliciones se forman antes de las elecciones y esto podría generar un proyecto común de gobierno.

- Al formar las coaliciones, se puede elegir qué tipo de modalidad pueden aplicar (total, parcial o flexible), esto da pauta a una mayor o menor participación por parte de los candidatos de los partidos políticos que conforman una coalición.

\section{Desventajas de los partidos políticos en coalición}

- La mayoría de las coaliciones electorales se disuelven cuando ganan las elecciones.

- El candidato es elegido por la coalición y no por el partido político al que pertenezca el candidato, ya que en las coaliciones los partidos políticos que las integran no siempre tienen las mismas ideologías y esto genera el conflicto a la hora de elegir candidatos, ya que el partido más grande predomina sobre el más pequeño y por ende les darán menor participación.

- Los partidos políticos que conforman la coalición no tienen una misma ideología, por lo tanto, en su plan de trabajo hay actividades que mermarían la ideología de algún partido

político que forme parte de la coalición.

\section{CONCLUSIONES}

La importancia de la asociación como derecho natural, y llevado a la práctica como un derecho político-electoral, es el punto en el cual los ciudadanos y el Estado se vinculan entre sí, ya que el derecho de asociación permite a los individuos autorizados para ello participar e intevenir en los asuntos políticos del país y alcanzar los fines comunes por una unión de fuerzas.

El derecho de asociación en materia políticoelectoral ha ido evolucionando como un derecho natural de contenido progresivo, reflejo de la situación social y del contexto histórico.

El objetivo de asociarse en materia política es la protección de los derechos y resistirse a la opresión, sin embargo, aun cuando se reconoce que el derecho de asociación o de reunirse no se puede coartar, ciertas variantes determinadas 
en la figura de la coalición ofrecen ventajas y desventajas, pues sus límites y conciliación con otros derechos, conlleva a oportunos señalamientos.

En las diferentes variantes de la asociación que revisamos en materia político-electoral pudimos observar que, dependiendo del fin de la asociación, cada una de las partes asociadas deberá ser tolerante ante las ideologías de los demás.

Las confusiones conceptuales del derecho de asociación y reunión en la legislación mexicana, nos llevan a señalar que el derecho de asociación en materia política, y en específico la figura de la coalición se presta a confusiones.

La coalición, es una forma de asociación que le brinda a los partidos políticos una oportunidad de tener mejores resultados electorales, pues del convenio de coalición, los partidos pueden lograr una mayor representación con alianzas preelectorales que incrementan sus oportunidades de lograr la mayoría de los escaños.

Es importante observar los resultados electorales de 2018 y relacionarlos con el derecho de asociación, pues en este caso se puede demostrar que haber ejercido este derecho, fue uno de los factores determinantes para lograr el triunfo en la contienda electoral.

Los partidos políticos en su intención de coaligarse asignan en proporción de la representatividad de cada partido, el porcentaje de los candidatos que han de postular conforme a los acuerdos previos entre partidos, sin embargo, una vez que la coalición obtiene el triunfo en las elecciones, un partido político más que fortalecido, habrá de compartir el poder con los candidatos electos que ocuparán las posiciones legislativas.
El derecho a la asociación y las asociaciones políticas nacionales, requieren mayor estudio por parte del derecho constitucional mexicano, y que esto se refleje en una clara regulación en el ordenamiento nacional en materia político- electoral.

La democracia en México, depende del reconocimiento de muchos otros derechos, tales como la protección y ejercicio del derecho de asociación y reunión de los ciudadanos, pues esto implica garantizar el ejercicio de una libertad que es inherente al ciudadano.

El derecho de asociación tiene su fundamento en el derecho natural, por lo cual debe admitirse sin más limitaciones que las impuestas por el propio derecho.

Se confirma la naturaleza social del hombre, cuando se ve exponencialmente ejercido el derecho de asociación, desde una primaria agrupación de ciudadanos con fines políticos hasta las formas más complejas de esta figura, como pueden ser las coaliciones electorales, figuras que reflejan una evolución cognitiva y de organización del ser humano para lograr fines conjuntos, pero que la investigación nos demuestra que todo surge de una característica esencial e inhata del hombre, lo social.

Se concluye la existencia de un derecho de asociación fundado no solo en el derecho natural, sino también respaldado por el ordenamiento jurídico positivo; pero que en el caso de México, dicho ordenamiento jurídico requiere ser reformulado en el sentido de ofrecer una mejor delimitación del derecho humano de asociación y reunión, ya que este derecho en materia política y en específico en la figura de la coalición como se encuentra previsto actualmente, da lugar a confusiones que desvirtúan la finalidad que persigue el derecho de asociación. 


\section{BIBLIOGRAFÍA}

- ACE Red de Conocimientos Electorales. (2018). Partidos y candidatos, partidos $\mathrm{y}$ candidatos en el proceso electoral, coaliciones y alianzas electorales". Recuperado de: http://aceproject.org/ ace-es/topics/pc/default

- Asamblea General de las Naciones Unidas. (1948). Declaración Universal de los Derechos Humanos. Nueva York, 10 de diciembre de 1948.

- ----------- (1966). Pacto Internacional de los Derechos Civiles y Políticos. Nueva York, 6 de diciembre de 1966.

- Bunker, K. y Navia, P. (2010). Explicando la desproporcionalidad en América Latina: magnitud de distrito, mala distribución y fragmentación partidaria. Revista Española De Ciencia Política, (23)

- Conferencia Internacional Americana. (1948). Declaración Americana de los Derechos del Hombre de 1948.

- Congreso Constituyente. (1857). Constitución Política de la República Mexicana. Diario Oficial de la Federación, 5 de febrero de 1857.

- - - (1917). Constitución Política de los Estados Unidos Mexicanos. Diario Oficial de la Federación, 5 de febrero de 1917.

- Congreso General de los Estados Unidos Mexicanos. (2015). Ley General de Partidos Políticos. Diario Oficial de la Federación.

- Instituciones y Procedimientos Electorales. Diario Oficial de la Federación.

- -------------. (1977). Ley Federal de Organizaciones Políticas y Procesos Electorales de. Diario Oficial de la Federación, 30 de diciembre de 1977.

- Conferencia Especializada Interamericana sobre Derechos Humanos. (1969). Convención Americana sobre Derechos Humanos. Pacto de San José. San José de Costa Rica, 22 de noviembre de 1969.

- Corona, L. (2016). Historia del marco jurídico de los partidos políticos en México. Misión Jurídica, 9, (10), 27-41,

- Edition MX, Huffpost. (2018). "Les ponen reglas claras a las coaliciones". Recuperado de: https://www.huffingtonpost.com. $\mathrm{mx} / 2017 / 10 / 30 /$ les-ponen-las-reglasclaras-a-las-coaliciones_a_23261028/

- Instituto Nacional Electoral. (2018). "Convenios de coalición". 12 de junio. Recuperado de: https://www.ine.mx/ actores-politicos/partidos-politicos/ convenios-de-coalicion/

- Instituto Nacional Electoral. (2018). "Convenios de coalición". 24 de junio. Recuperado de: https://www.ine.mx/ actores-politicos/partidos-politicos/ convenios-de-coalicion/

- Instituto Nacional Electoral. (2018). "Convenios de coalición". 12 de julio. Recuperado de: https://www.ine.mx/ actores-politicos/partidos-politicos/ convenios-de-coalicion/

- Gómez, C. (2013). Introducción a la teoría política. México: Oxford.

- Núñez, S. (2011). El derecho de asociación. Revista De Derecho, 32 (1), 49-83.

- Suárez, M.y Jiménez, R. (1994.) Constitución de 1857, edición facsimilar náhuatlespañol. México: ed. Instituto de Estudios Constitucionales,

- Ramos, E. (2011). Las coaliciones en México: áreas de oportunidad para una reforma electoral y legislativa. Revista Pluralidad y Consenso, 3 (14), 26 - 30.

- Red Innovación. (2018) Ventajas y desventajas de las coaliciones. Recuperado 27 de junio de 2018, En: https://www.redinnovacion.org/dato/ ventajas-y-desventajas-de-las-coaliciones

- Vasconi, T. (1992). Los sindicatos profesionales. Argentina: Valerio Abeledo. Instituto de Investigaciones Jurídicas. (2001). Diccionario Jurídico Mexicano.15ำ ed. México: Porrúa. 